MAGNARTO प्राम

(4)

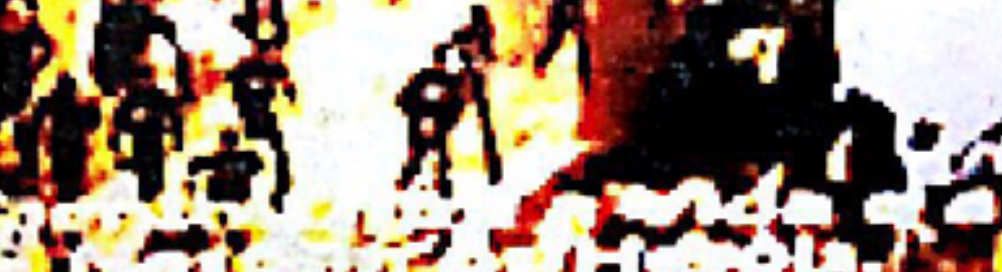

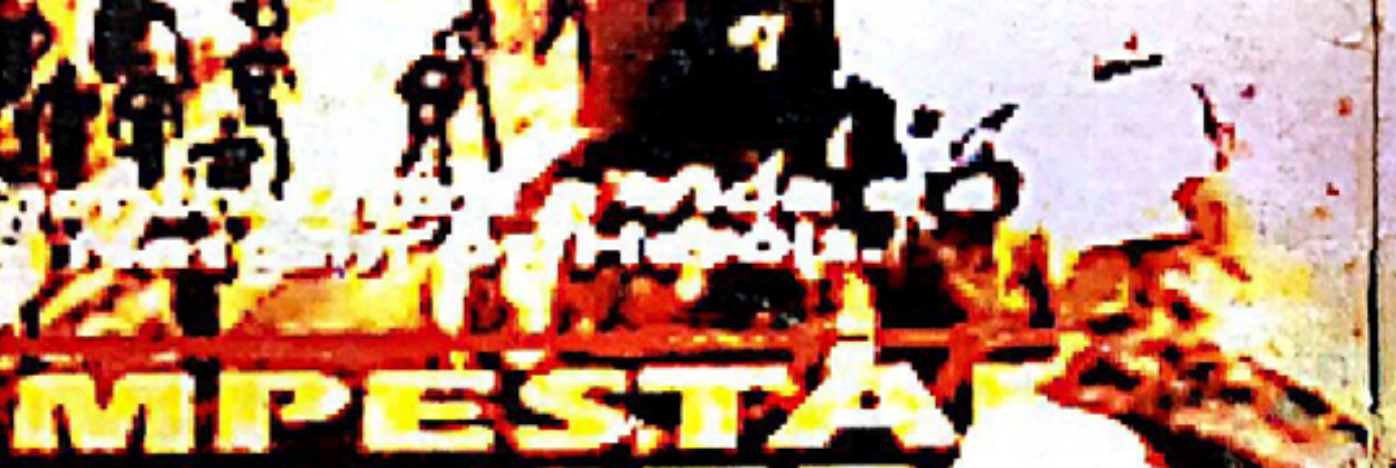

$2 D S T=15$

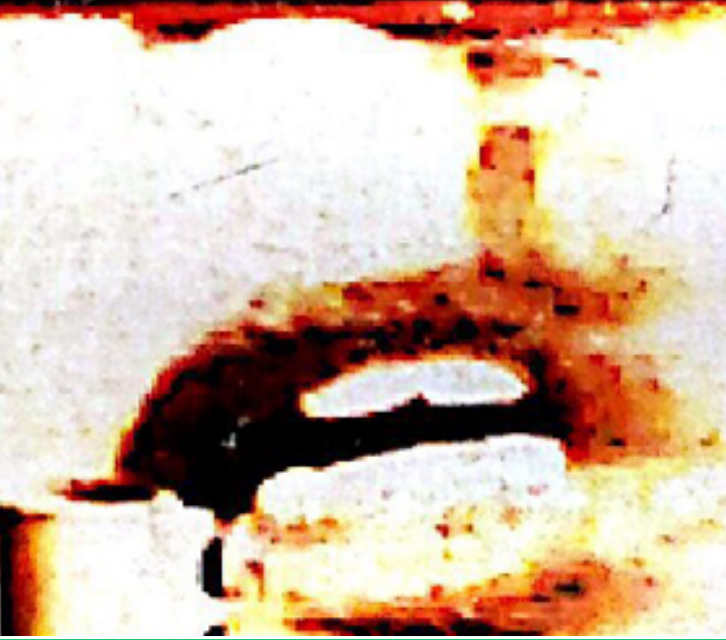

A estética do imaginário no cinema

Demian Garcia e André A. Medeiros P. 94

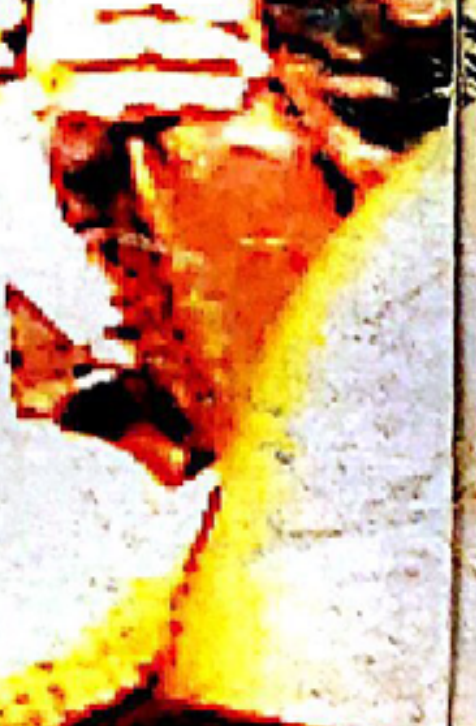

$+$

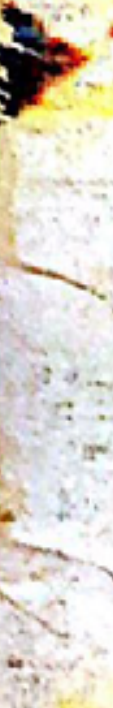

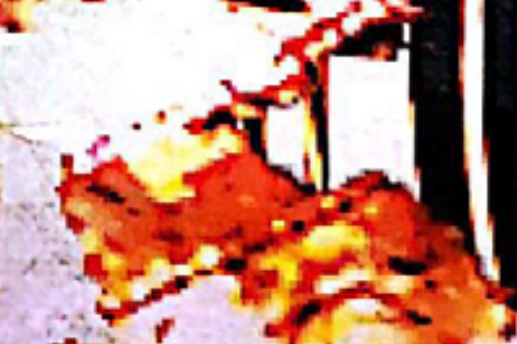

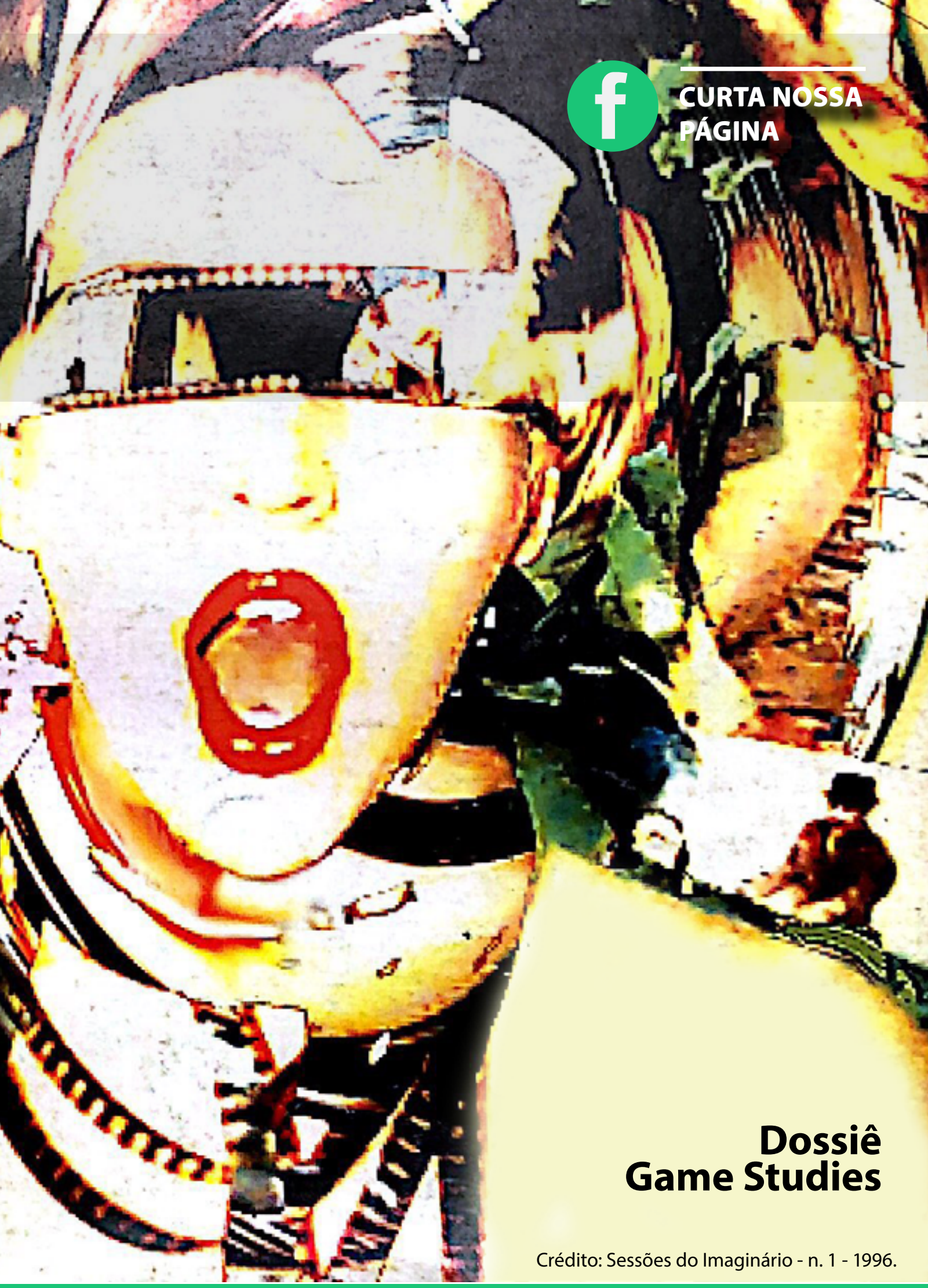

Materialidades fílmicas, magia e montagem

Ednei de Genaro

P. 112

Videogames, transgressão e criatividade no Brasil

Emmanoel Ferreira 


\section{Desenhos Animados e Representação Feminina: uma trajetória em produções brasileiras}

Cartoons and Female Representation: a trajectory in Brazilian productions

Potiguara Mendes da Silveira Junior ${ }^{1}[$ Laryssa Gabriele Moreira do Prado ${ }^{2}[\pi$

\section{Resumo}

Em 2017, comemora-se o centenário da exibição da primeira animação brasileira. Oartigo analisa o momento em que a representação feminina tem início nestas animações e seus desdobramentos até hoje. Após uma revisão de literatura, observa-se que, em geral, as personagens nacionais têm se distanciado dos estereótipos de gênero, sendo "Mônica" uma de suas mais conhecidas. Este fato acompanha a mudança do cenário da representação do feminino na animação mundial.

\section{Palavras-chave}

Personagens femininas; animação brasileira; representação feminina.

\section{Abstract}

In 2017, the centenary of the first Brazilian animation is celebrated. The article analyzes the moment in which the feminine representation begins in these animations and their unfoldings until today. After a review of the literature, it is observed that, in general, the national characters have distanced themselves from gender stereotypes, being "Monica" one of their best known. This fact accompanies the change in the scenario of female representation in world animation.

\section{Keywords}

Female characters; brazilian animation film; female representation.

130 PORTO ALEGRE | v. 22 | n. 38 | 2017 | p. 130-141 DOI: http://dx.doi.org/10.15448/1980-3710.2017.2.28955 Sessões do Imaginário 
Pouco antes de os irmãos Lumière exibirem o filme L'Arrivée d'un train en gare de La Ciotat (Irmãos Lumière, 1895), a animação já dava os primeiros passos na França. Em 28 de outubro de 1892, Émile Reynaud (18441918) apresentou no Museu Grévin (Paris) a primeira projeção em seu teatro óptico, aparelho que possibilitava a exibição de imagens animadas. A importância da projeção foi tal que, não por acaso, nesta data é comemorado o "Dia Internacional da Animação". Mas a verdadeira paternidade desta modalidade do cinema é atribuída a outro francês, Émile Cohl (1857-1938), cujo filme Fantasmagorie (Émile Cohl, 1908), com dois minutos de duração, empregou dois mil desenhos (Silva, 1999). Ele também é responsável pelo primeiro filme de animação de bonecos, realizado em 1910 (Moreno, 1978).

A palavra animação tem origem no latim animare, "dar vida". No século XX, associada ao fenômeno da persistência retiniana (tempo em que as imagens permanecem na retina), passa a ser utilizada para descrever imagens em movimento (Solomon, 1987): os seres humanos são capazes de registrar 12 imagens por segundo, e sequências que ultrapassam este número criam a ilusão de que objetos estáticos estão se movendo.

O desenvolvimento de produções de cinema de animação no mundo foi condicionado às possibilidades técnicas de cada país. "A paternidade do desenho animado é da França, mas é nos Estados Unidos que vai encontrar uma estrutura industrial forte que favorecerá a sua criação e seu desenvolvimento" (Moreno, 1978, p. 50). O Brasil inicia sem grande estrutura, e só a partir do século $X X I$ suas produções buscam acompanhar mais de perto as tendências mundiais de estética e linguagem. É quando nomes de grandes animadores - Alê
Abreu, Luiz Bolognesi, Nancy Kato, Carlos Saldanha entre outros - começam a ser reconhecidos no exterior.

Uma dessas tendências mundiais não é técnica, tem a ver com a construção da narrativa: um novo modo de apresentar as personagens femininas em produções infantis, adolescentes ou adultas, exibidas tanto nas séries quanto no cinema. Este novo modo vem rompendo com o arquétipo das tradicionais princesas indefesas e dependentes do príncipe, apresentando-as como mulheres corajosas e solucionadoras. É uma mudança diretamente relacionada ao fortalecimento dos debates feministas que ocorrem no Ocidente a partir do final do século XIX (a primeira onda feminista aconteceu principalmente nos Estados Unidos e no Reino Unido).
Traçaremos, a seguir, um breve panorama da história do desenvolvimento das animações no Brasil com o intuito de averiguar em que momento, como e por quê essa virada temática ocorreu (se é que, realmente, foi uma virada).

\section{A chegada ao Brasil}

Em 8 de julho de 1896, acontecia no Rio de Janeiro a primeira sessão de cinema do Brasil. A iniciativa de projetar filmes de cerca de um minuto sobre cenas do cotidiano europeu partiu de um itinerante belga, Henri Paillie. Um ano depois, Paschoal Segreto (1868-1920) e José Roberto Cunha Salles inauguram, na mesma cidade, uma sala permanente para a exibição de filmes. Em

131 PORTO ALEGRE | v. 22 | n. 38 | 2017 | p. 130-141 Sessões do Imaginário 
1898, Afonso Segreto - irmão de Paschoal - rodou Vista da Baía da Guanabara (Afonso Segreto, 1898), a primeira produção cinematográfica brasileira, realizada de dentro de um barco que chegava ao Rio de Janeiro, registrando pontos importantes da cidade.

A precariedade do fornecimento de energia elétrica fez com que só em 1907, com a inauguração da Usina de Ribeirão das Lages, novas salas de exibição fossem abertas no Rio de Janeiro e São Paulo, estimulando a produção e comercialização de filmes estrangeiros e nacionais (Gomes, 2008). No mesmo ano, o cartunista Raul Pederneiras realiza pequenas charges animadas para encerrar as exibições em cada sessão do Pathé-Jor$n a{ }^{3}$.

Entretanto, o primeiro filme de animação é exibido apenas uma década depois. Em parceria com o político e empresário Sampaio Corrêa, Álvaro Marins, o Seth, cartunista do jornal A Noite e da Casa Mathias, apresenta no Rio de Janeiro o filme Kaiser (Álvaro Marins, 1917), charge animada em que o líder alemão Guilherme II se senta em frente a um globo e coloca um capacete representando o controle sobre o mundo. O globo cresce e engole o Kaiser. Era uma crítica sarcástica ao expansionismo alemão em meio à Primeira Guerra Mundial (1914-1918). “Lançado em 22 de janeiro de 1917, já no dia 24 era anunciado seu último dia de exibição" (Moreno, 1978, p. 67).

Segundo o crítico e historiador Jean-Claude Bernardet (2009, p. 21), "não é possível entender qualquer coisa que seja do cinema brasileiro se não se tiver em mente a presença maciça e agressiva, no mercado interno, do filme estrangeiro". Na animação não é diferente. Também na capital carioca, em 1917, o grupo Kirs Filmes produz Chiquinho e Jagunço ou Traquinagens de Chiquinho e seu inseparável amigo Jagunço (Kirs
Filmes, 1917), primeira animação com personagens e situações típicas brasileiras vindas da revista Tico-Tico (primeira a publicar histórias em quadrinhos no país). A animação seguia a tendência, iniciada nos Estados Unidos, de transpor para a tela personagens que só existiam no papel: “O desenho animado é o quadrinho dinamizado por meios mecânicos" (Moreno, 1978, p. 28). Essa influência ocorreu também na animação As aventuras de Billie e Bolle (Eugênio Fonseca Filho, 1918), inspirado nos personagens Mutt e Jeff, e em Macaco Feio, Macaco bonito (Luis Seel e João Stamato, 1929), realizada no estilo dos irmãos Max e David Fleischer'.

A indústria norte-americana do cinema se ramificava pelo mundo. “Lá [nos Estados Unidos], a animação já havia se tornado um negócio e a realização artística se tornara apenas outra faceta da atividade. Antes mesmo do nascimento da animação brasileira, a norte-americana já atingira certa maturidade" (Athayde, 2013, p. 8). O sistema industrial dos primeiros estúdios norte-americanos surge em 1910, com as contribuições de John Randolph Bray (1879-1978), que estabelece a animação como um negócio competitivo. Ele abre seu próprio estúdio em 1914, no mesmo ano em que Raoul Barré (1874-1932) funda o primeiro estúdio exclusivamente de animação em parceria com o animador Bill Nolan (1894-1954). É nesse contexto que as séries de desenhos animados surgem como um novo formato que era

resultado das melhorias no fazer de animação trazidas pelo desenvolvimento da indústria - em especial o uso de acetato - e a novas práticas empresariais dos estúdios como a Bray Productions. [...] a indústria norte-americana, com sua eficiência recém-adquirida, transformará a série animada em um produto de consumo em massa (Athayde, 2013, p. 20).
No Brasil, grande parte das animações iniciais tinha como destino o mercado publicitário. Além das produções de Eugênio Fonseca Filho, o Fonk, já mencionado, filmes encomendados a Pasqualle Michelle Faletti, e as charges produzidas pelo cearense Luiz Sá (1907-1979), exibidas nos intervalos entre as notícias do Globo Esportivo, Esporte na tela e Notícias da semana, são exemplos do caráter comercial das animações das décadas de 1920 e 1930. Nesse período, fora da publicidade, destaca-se a série em forma de charges animadas intitulada Brasil Animado, de Luiz Seel.

Na década de 1930, Walt Disney visita o Brasil visando "estreitar os laços entre os países das três Américas e angariar simpatia para oposição à crescente política nazista de Hitler" (Gomes, 2008, p. 7). Isto, além de conhecer os trabalhos de animação de artistas brasileiros. Luiz Sá tentou exibir para ele o curta Virgulino apanha (Luiz Sá, 1938), mas teve seu pedido recusado pelo DIP (Departamento de Imprensa e Propaganda), do governo Vargas, sob a justificativa de que o desenho era muito rudimentar. Sá também não conseguiu distribuir seus filmes.

Em 1942, Humberto Mauro (1897-1983), um dos pioneiros no cinema brasileiro, lançou O dragãozinho manso (Humberto Mauro, 1942), primeiro stop-motion ${ }^{5}$ nacional com animação de bonecos, com 18 minutos de duração. Em 1953, é realizado o primeiro longa-metragem de animação brasileiro: Sinfonia Amazônica (Anélio Latini, 1953) com contribuição de Mário Lattini Filho. Em preto e branco, o filme foi feito com películas de vários tipos e de baixa qualidade. "Enquanto em grandes animações estrangeiras eram, na época, utilizados cerca de 400 animadores, o artista trabalhou sozinho na concepção, preparação e elaboração dos personagens e dos cenários" (Gomes, 2008, p. 8).

132 PORTO ALEGRE | v. 22 | n. 38 | 2017 | p. 130-141 Sessões do Imaginário 
Quando o Brasil conseguiu finalizar seu primeiro longa-metragem animado, a Disney lançava Peter Pan (Clyde Geronimi; Wilfred Jackson; Hamilton Luske, 1953), seu 14\% filme do tipo, e em cores (Mendes, 2013). O panorama político nacional influenciava diretamente o desenvolvimento das atividades no setor, oscilando entre a oferta de facilidades, e a imposição de barreiras. Apesar das leis de incentivo, em 1932 ${ }^{6}, 1939$ e 1946, só a partir do fim da década de 1960 é que as produções nacionais ganham mais força, como o I Festival Internacional de Cinema de Animação no Brasil, que contava com diversas realizações do Centro Experimental de Ribeirão Preto. Uma iniciativa de Rubens Francisco Luchetti, Bassano Vaccarini, com a participação de Roberto Miller, premiado artista brasileiro que passou seis meses na National Film Board, do Canadá, sendo instruído pelo renomado Norman McLaren (1914-1987).

Ainda sem o domínio da técnica, só na década seguinte a animação passa a caminhar a passos mais contínuos. A cidade de São Paulo se torna o grande berço dos animadores. Destacam-se estúdios como o Briquet Produções, de Daniel Messias, Walbercy Ribas e o Maurício de Sousa Produções. Ainda em 1970, o amazonense e autor de quadrinhos Álvaro Henriques Gonçalves lá finalizaria o segundo longa-metragem brasileiro e pioneiro em cores, Presente de Natal (Álvaro H. Gonçalves, 1970). Dois anos depois, Piconzé (Yppe Nakashima, 1972) chega aos cinemas, uma das primeiras animações nacionais a ter repercussão entre o público (Moreno, 1978). O longa também inovou ao contar com uma grande equipe de animadores treinados especialmente por seu ilustrador e diretor, o japonês Yppe Nakashima.

Apesar da produção de curtas-metragens ${ }^{7}$ ter sido mais frequente neste período, os longas de animação só tiveram continuidade em 1982, com as aventuras da
Turma da Mônica, de Maurício de Sousa, além de duas animações com os atores do grupo Os Trapalhões. Nos anos seguintes, a crise financeira no Brasil, que se agravou durante a Era Collor, fez com que os investimentos no setor caíssem drasticamente. A produção dos anos 1990 sofreu com o fim da Embrafilme, e o mercado teve que se reinventar.

Em 1996, estreia Cassiopeia (Clóvis Vieira, 1996), primeiro longa-metragem feito integralmente em computador (Gomes, 2008) ${ }^{8}$, abrindo novas possibilidades técnicas para animação. Com a direção de Clóvis Vieira, uma equipe de três diretores de animação e onze animadores, trabalhando em dezessete microcomputadores, a produção demorou seis anos para ficar pronta.

Com a evolução da tecnologia digital no fim dos anos 1980 e início dos anos 2000, os destaques vão para, além dos longas-metragens da Turma da Mônica (Maurício de Sousa, 2004; 2005; 2007; 2008; 2009), Xuxinha e Guto Contra os Monstros do Espaço (Clewerson Saremba; Moacyr Góes, 2005), Wood \& Stock: Sexo, Orégano e Rock'n'Roll (Otto Guerra, 2006), e Brichos (Paulo Munhoz, 2007). Em 2014, Uma história de amor e fúria (Luiz Bolognesi, 2013) se destacou como melhor longametragem no Annecy, na França, considerado o maior festival de animação do mundo. No ano seguinte, $\mathrm{OMe}$ nino e o Mundo (Alê Abreu, 2013), foi premiado no mesmo festival como melhor longa pelo público e pelo júri, sendo vendido para oitenta países. Na França, o filme levou cem mil pessoas aos cinemas (Camargo, 2017), e em 2016 foi um dos cinco selecionados para a categoria Melhor Animação do Oscar. No início de 2018, em época de indicação e realização do Oscar, O Touro Ferdinando, dirigido por Carlos Saldanha, foi indicado à categoria de melhor filme de animação.

Outro sucesso brasileiro é o curta-metragem Cas- tillo y el Armado (Pedro Harres, 2014), que já conquistou cinquenta e cinco prêmios e menções e foi selecionado em mais de duzentos festivais. Mais recentemente, Leo Matsuda ficou entre os dez pré-classificados na categoria melhor curta-metragem de animação do Oscar 2017, com Cabeça ou Coração (Inner Workings, Leo Matsuda, 2016), produzido pela Disney.

Em 2015, o país também teve destaque com Guida, de Rosana Urbes, que ganhou o prêmio de melhor curta-metragem de estreia no Annecy - prêmio Jean-Luc Xiberras - e menção especial da Federação Internacional de Críticos de Cinema (Fipresci), sendo o único curta brasileiro a ganhar dois prêmios no festival. Além disso, em junho de 2018 o Brasil foi escolhido como país homenageado no Annecy.

\section{A televisão, as personagens femininas,} as séries

A construção das personagens femininas na história da animação, como um todo, se deve principalmente aos estúdios Disney, que "revolucionaram o mercado cinematográfico com seus filmes de longa-metragem como Branca de Neve e os Sete Anões (David Hand, 1936), todos de estrondoso sucesso" (Athayde, 2013, p. 20). Existem, entretanto, diferenças acentuadas entre as primeiras figuras femininas produzidas e as atuais personagens. Entre os fatores responsáveis estão as mudanças ocorridas no século $X X$, propiciadas pela expansão do capitalismo, das revoluções científicas e tecnológicas, do papel desempenhado pela cultura no campo social e finalmente, o surgimento do movimento feminista e suas diferentes fases, ou "ondas". Destaca-se a ruptura histórica na forma como a identidade feminina é construída, o que inicia uma transformação no modo de socialização e individualização do femini- 
no (Lipovetsky, 2000).

Como reflexo destas mudanças, de acordo com Lopes (2015), as princesas da Disney podem se dividir entre três fases: "clássicas" (Branca de Neve, Cinderela e Aurora, de 1937 a 1959), "rebeldes" (Ariel, Bela, Jasmine, Pocahontas e Mulan, de 1989 a 1998), e "contemporâneas" (Tiana e Anna, de 2009 a 2013).

As princesas "rebeldes" não são mais tão submissas e indefesas quanto suas sucessoras. Ariel, Jasmine e Pocahontas contrariam as ordens dos pais; Bela é tida como estranha em sua vila por gostar de ler e sonhar em conhecer o mundo; e Mulan, considerada estabanada pela casamenteira, acaba travestida de homem, no exército chinês. Mas é só com o filme Frozen (Chris Buck; Jennifer Lee, 2014), que a produção cinematográfica massiva de animação nos Estados Unidos rompe com a ideia do amor romântico e da necessidade de um homem para salvar uma princesa em perigo ao contar a história de duas princesas, as irmãs Anna e Elsa, que encontram o final feliz graças ao amor verdadeiro e forte vínculo entre elas, não através da busca de um príncipe encantado (Castro, 2016, p. 512).

Esse novo viés sobre o feminino seria um reflexo da mudança da

[...] imagem da mulher moderna que, está cada vez mais envolvida com novas práticas de comportamento e escolhas pessoais, como por exemplo, novas formas de percepção estética e de relacionamentos sociais, práticas estas comumente associadas à construção da identidade feminina. E são esses novos modelos de identificação do feminino que têm despertado não somente o interesse do público infantil, mas também, de jovens e adultos de todas as idades e gênero, exatamente pelas particularidades que tais animações compartilham com a realidade social contemporânea (Fernandes, 2015, p. 12).

Fora dos cinemas, nas séries de desenhos animados, as personagens femininas estadunidenses também refletem uma mudança de paradigmas devido ao fortalecimento do debate social sobre as questões de gênero. Seguindo o exemplo de Jean Grey (X-Men, Stan Lee; Jack Kirby, 1963), Velma (Scooby Doo, Joseph Barbera; Willian Hanna, 1969), She-ra (He-Man, Roger Sweet, 1985) e Lisa (Simpsons, Matt Groening, 1989), diversas personagens vêm quebrando o arquétipo da princesa nos Estados Unidos: Vandinha (Família Adams, The
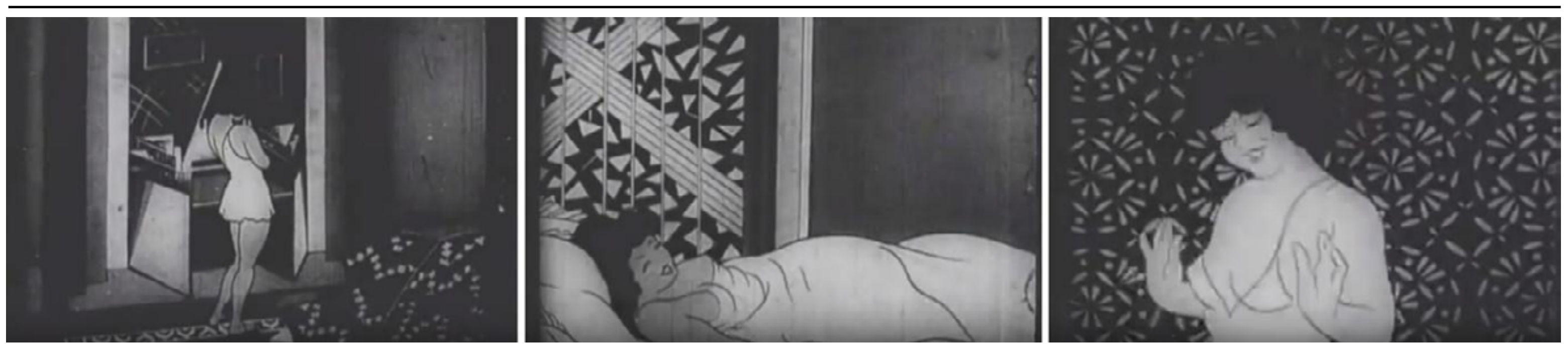

Figura 2: Frames de Frivolitá (1930), de Luis Seel. Fonte: Dia da Animação (2014).

134 PORTO ALEGRE | v. 22 | n. 38 | 2017 | p. 130-141 Sessões do Imaginário 
Addams Family, Charles Addams, 1992), Daria (Glenn Eichler; Susie Lewis Lynn, 1997), Meninas Super Poderosas (The Powerpuff Girls, Craig McCracken, 1998), Sandy (Bob Esponja Calça Quadrada, SpongeBob SquarePants, Stephen Hillenburg, 1999), Dora Aventureira (Dora, the Explorer, Chris Gifford; Valerie Walsh; Eric Weiner, 2000), até as mais recentes Princesa Jujuba e Marceline (Hora da Aventura, Adventure Time, Pendleton Ward, 2010), Mabel Pinnes e Grenda (Gravitty Falls, Alex Hirsch, 2012) e Star Butterfly (Star vs As Forças do Mal, Star vs. The forces of Evil, Daron Nefcy, 2015).

Ainda no cinema, no Brasil, Frivolitá (1930), de Luis Seel, conta em pouco mais de 40 segundos a história de uma jovem que tenta dormir, mas tem seu sono impedido por um gramofone, gatos e objetos animados. Numa época em que ainda não existiam os longa-metragem ou as séries televisivas, esta talvez seja a primeira representação feminina de destaque na animação nacional (similar a Betty Boop, que surgiu na mesma época nos Estados Unidos). A única personagem da trama é apresentada com longos cílios e uma camisola curta: uma cena íntima, aparentando vaidade, fragilidade e sensualidade. Tais características ditas femininas são ainda reforçadas pelo título: frívolo é o que não tem importância, que é sem valor, leviano, fútil, inconstante, volúvel (Frívolo, 2018).

A primeira transmissão de TV no Brasil ocorre em 18 de setembro de 1950, por iniciativa de Francisco de Assis Chateaubriand Bandeira de Melo, responsável pelo conglomerado de mídia Diários Associados. Só em 1977, é transmitida a primeira animação nacional: o especial da Turma da Mônica, Feliz Natal pra Todos ou O Natal da Turma da Mônica (Maurício de Sousa, 1976), de pouco mais de cinco minutos. Encomendada após o sucesso imediato dos quadrinhos na década de 1960, foi reprisada durante alguns anos nas vésperas de natal pela Rede Globo e pela TV Tupi. As histórias completas teriam começado a ser produzidas em 1976 e distribuídas através de compilações de filmes durante os anos 1980 e 1990 - como Mônica e a Sereia do Rio (Maurício de Sousa, 1986). Os Estúdios Maurício de Sousa se tornariam o maior produtor de longas de animação no Brasil da década de 1980, todos de grande sucesso comercial (Athayde, 2013).

Desta forma, na televisão nacional a primeira personagem feminina de destaque foi Mônica9 ${ }^{9}$ que, em 1963, estreou a tirinha do Cebolinha publicada na Folha da Manhã, atual Folha de São Paulo, e, em 1977, foi para a TV com Turma da Mônica. "Já em sua primeira aparição, ela mostrou que as meninas podiam ter seu espaço e que não é preciso corresponder a padrões de beleza para ser dona da rua" (Maurício..., 2006) (em 2006, a Maurício de Sousa produções criou o projeto \#DonasdaRua, com a intenção de produzir e agregar, através de histórias e exemplos, como meninas do Brasil e do mundo podem exercitar seu direito de ser o que quiserem, e entender melhor conceitos como empoderamento e igualdade de oportunidades). Mônica tem que lidar com os garotos do bairro que a insultam por causa de seus atributos físicos, mas não mede esforços para ser mais forte do que eles. Por gostar de comer muito, Magali, sua melhor amiga, também sofre com a implicância dos amigos, mas tampouco parece se abalar.

Maurício de Sousa, cartunista e criador da personagem, conta que Mônica veio para atender uma demanda específica:

[...] alguém da redação da Folha me lembrou de um detalhe que eu estava deixando passar despercebido: Cadê os personagens femininos nos seus qua- drinhos? Cadê as mulheres? Você é misógino? Perguntavam-me. Primeiro corri ao dicionário para ver o que significava a palavra. Misógino, diz o dicionário, é quem tem aversão ou desprezo pelas mulheres. Como não era o meu caso, parei para pensar sobre o porquê de não haver mulheres nas minhas primeiras histórias (Sousa, 1996, n.p.).

A explicação do autor vem do fato de que ele reproduzia nas tirinhas parte de sua infância, de suas memórias, opiniões e brincadeiras, que eram vivências de um menino. "Não sabia exatamente como eu (quando autor) deveria me comportar ou relacionar quando incorporado por uma mulher. Mas a situação tinha que ser enfrentada. E resolvida" (Sousa, 1996, n.p.). Foi então que encontrou inspiração dentro da própria casa, nas filhas.

A década de 1970, momento em que Mônica chega à televisão brasileira, é considerada por autores como Cynthia Andersen Sarti (1998), o início do movimento feminista no Brasil. De acordo com Ana Alice Alcantara Costa (2005), seria mais viável dizer que é nessa década que o movimento se fortalece no país. Carole Pateman (1996) explica que as feministas trouxeram à tona como as circunstâncias pessoais estavam estruturadas por fatores públicos, por leis sobre a violação e o aborto, pelo status de "esposa", por políticas relativas ao cuidado das crianças, pela definição de subsídios próprios do estado de bem-estar e pela divisão sexual do trabalho no lar e fora dele (Pateman, 1996). E ao trazer essas novas questões para o âmbito público, o feminismo exigiu, e ainda exige, a criação de novas condutas, novas práticas, conceitos e novas dinâmicas (Costa, 2005).

De acordo com Costa (2005), no Brasil, e em outros 
países latino-americanos, as primeiras manifestações feministas aconteceram por meio da imprensa feita por mulheres, na primeira metade do século XIX. No fim deste mesmo século, já inclusas no mercado de trabaIho e influenciadas por ideais anarquistas e socialistas que chegavam com os trabalhadores imigrantes, as mulheres se envolveram na luta sindical por melhorias nas condições de emprego, bem como contra a submissão que ocorria devido ao gênero. Esse engajamento se fortaleceu no início do século $X X$, sendo articulado à organização das classes populares.

Mas o golpe militar, em 1964, no Brasil, e o avanço das ditaduras em outros países latinos, silenciaram movimentos sociais, entre eles o feminismo. É nesse contexto que, a partir da década de 1970, nasce a segunda onda feminista, ampliando o movimento a um alcance de massa, unindo a resistência das mulheres frente à ditadura à sua maior participação no mercado de trabalho - mesmo com um intenso processo de exclusão - e acesso à educação, além da efervescência cultural - movimento hippie, uso de anticoncepcionais e liberdade sexual. O movimento articulou as lutas contra as formas de opressão das mulheres na sociedade com as lutas pela redemocratização. $E$ foi em meio a essa década de fortalecimento e contrariedades que Turma da Mônica chegou às telinhas, tendo como líder uma personagem feminina durona, diferente das representações anteriores.

A partir dos anos 1980, a terceira onda do feminismo expande os temas feministas para incluir um grupo diversificado de mulheres com um conjunto de identidades variadas. $O$ objetivo era promover mudanças nos estereótipos, nos retratos da mídia, na linguagem para definir as mulheres e abandonar a ideologia do "feminismo vítima", aplicada ao feminismo da segunda onda, em uma interpretação pós-estruturalista do gênero e da sexualidade. Emerge então a "terceira mulher".

A primeira mulher era diabolizada e desprezada; a segunda mulher, adulada, idealizada, instalada num trono. Mas em todos os casos a mulher era subordinada ao homem, pensada por ele, definida em relação a ele: não era nada além do que o homem queria que fosse. Essa lógica de dependência diante dos homens já não é mais o que rege mais profundamente a condição feminina nas democracias ocidentais. Desvitalização do ideal da mulher do lar, legitimidade dos estudos e do trabalho femininos, direito de voto, "descasamento", liberdade sexual, controle da procriação: manifestações do acesso das mulheres à inteira disposição de si em todas as esferas da existência, dispositivos que constroem o modelo da "terceira mulher" (Lipovetsky, 2000, p. 236)

O fortalecimento da animação nacional vem ocorrendo junto à essa onda, que perdura até os dias atuais. Com a criação da Agência Nacional do Cinema (Ancine), em 2001 - agência reguladora que fomenta, regula e fiscaliza a indústria cinematográfica e videofonográfica -, as produções brasileiras tiveram um aumento de qualidade, estimulado por constantes aquisições de canais abertos como Rede Globo e TV Brasil, e de canais pagos como Cartoon Network e Discovery Kids. A primeira série produzida inteiramente no Brasil a atingir sucesso de público foi Peixonauta (Celia Catunda; Kiko Mistrorigo, 2009), da TV PinGuim, em associação com a Discovery Kids. No ano seguinte, já era líder de audiência na emissora, ganhando o prêmio de melhor programa infan- til de televisão pela Associação Paulista de Críticos de Arte. Atualmente, é exibida em mais de oitenta países.

As séries de animação brasileiras também têm se destacado no exterior. Além de Peixonauta (Celia Catunda; Kiko Mistrorigo, 2009), O Show da Luna (Celia Catunda; Kiko Mistrorigo, 2014), Irmão do Jorel (Juliano Enrico, 2014), Princesas do Mar (Fábio Yabu, 2007) e Meu AmigãoZão (Andrés Lieban, 2010) são alguns dos exemplos que romperam as fronteiras, sendo exibidos em países da América Latina, Europa, Estados Unidos, Canadá, Austrália, entre outros.

Caminhando ao lado da terceira onda do feminismo, surgem na animação nacional conteúdos liderados por personagens femininas de destaque, como o desenho De Onde Vem? (Kiko Mistrorigo; Célia Catunda, 2001), focado em Kika, uma menina na faixa de seis anos que se mostra questionadora, curiosa, e quer entender o mundo. Da mesma produtora, em 2014, OShow da Luna (Kiko Mistrorigo; Célia Catunda, 2014) traz uma temática similar, com uma protagonista apaixonada por ciência que, a cada dia, quer saber "O que está acontecendo aqui?". O Diário de Mika (Elizabeth Mendes, 2015), também se propõe a abordar o fantástico mundo de descobertas e conquistas das crianças pela visão de uma personagem feminina.

Em Peixonauta, série já mencionada, Marina, única personagem feminina, é muito esperta e inteligente, mas ainda não é essencial à trama. $O$ contrário acontece com a personagem Xuxinha (José Isaac Huña e Ana Paula Desmet, 1998), baseada na apresentadora infantil Xuxa Meneghel, que é uma heroína. Mesmo que a maioria dos personagens do desenho seja do sexo masculino, Xuxinha é quem tem a voz de comando e sempre salva o dia.

Em Escola de Princesinhas (Video Brinquedo, 2007), 
em que as histórias são fiéis ao estereótipo da princesa dos contos de fadas - as próprias personagens são baseadas nos originais da Disney -, a líder da turma, Cindy, inspirada em Cinderela, é muito questionadora e não concorda em esperar passivamente o príncipe encantado. Ela gosta de aventuras, mesmo que isto vá contra o que os professores ensinam sobre o que é ser uma princesa. Ainda assim, é a mais vaidosa da turma, e vive sonhando em ter um sapato de cristal da última moda.

Zica e os Camaleões (Ari Nicolosi, 2010), realizado pelos estúdios Cinema Animadores e Conteúdos Diversos, é mais um exemplo de narrativa diferenciada. Zica é uma adolescente de 14 anos que se sente preto e branco em um mundo colorido. Alternativa, preocupa-se com o futuro e questiona o estilo de vida de seus pais e de alguns colegas de escola. Ela grafita, escreve e compõe músicas com sua banda.

Em Meu AmigãoZão (Andrés Lieban, 2011), produzido pelo estúdio 2D Lab, Lili, uma menina de cinco anos, divide a cena com Yuri e Matt, e seus amigos imaginários: Nessa, a girafa, Golias, o elefante, e Bongo, o canguru, respectivamente. No episódio A princesa perfeita (Temporada 1, episódio 5), Lili se inspira na imagem de uma princesa da caixa de uma boneca para se fantasiar em seu aniversário, e eleger um príncipe encantado. Mas Lili usa óculos, e as princesas não. Assim, ela resolve abrir mão do objeto e acaba não enxergando nada durante a festa. Depois de alguns tropeções, a menina recorre ao uso dos óculos e escolhe todos os amigos como príncipes. No fim, Lili diz: "Para princesa você ser, não tem muito que mudar. Basta ser quem você é, para o seu príncipe encontrar".

Em um segundo episódio, Conto de Fadas (Temporada 1, episódio 11), com medo de sujar seu ves- tido novo, Lili se recusa a brincar com os amigos no parque, e os obriga a entrar em um conto de fadas criado por ela. Mas, durante a brincadeira, a menina acaba perdendo toda a diversão por conta da preocupação com o vestido. No final, Lili deixa que Yuri e Matt escolham a brincadeira: imitar cachorros pelo chão. É possível concluir que, apesar de Meu AmigãoZão apresentar vestígios das princesas da Disney na construção de sua personagem feminina, ela mesma está sempre as desconstruindo.

No episódio Fúria e poder sobre rodas (Temporada 1, episódio 25), da série Irmão do Jorel (Juliano Enrico, 2014), um dos grandes sucessos nacionais na atualidade, a personagem Lara, quando questionada sobre ser "mulherzinha", ou uma pessoa que faz coisas "de menina", rebate: "você chama alguém de mulherzinha quando a pessoa é incrível". A mesma ainda alega gostar mais de jogar bola do que brincar com um pônei rosa em miniatura, e se mostra muito mais corajosa do que o protagonista da série e seu melhor amigo, o Irmão do Jorel, rompendo com estereótipos de feminilidade.

Como é possível observar, desde os anos 1960, a representação feminina vem sendo constantemente ressignificada nas produções brasileiras, o que está diretamente relacionado à terceira onda feminista e às reivindicações por uma representação menos estereotipada do feminino. A personagem Mônica, por exemplo, se tornou embaixadora da agência Unicef (Fundo das Nações Unidas pela Infância - Organização das Nações Unidas) em 2007, e defende os direitos das crianças e adolescentes. Em 2016, a Mauricio de Sousa Produções assinou os Princípios de Empoderamento das Mulheres da ONU - uma iniciativa da ONU Mulheres e do Pacto Global que orienta o setor privado na promoção da igualdade de gênero no ambiente de trabalho, mercado e comunidade.

\section{Elas têm a força}

De modo geral, por terem surgido num contexto em que a mulher já estava sendo vista sob um olhar próprio (e não apenas segundo a perspectiva masculina), no qual as lutas feministas se intensificavam, os desenhos animados no Brasil apresentam uma tendência à não reprodução fiel de personagens indefesas e submissas. E como essas personagens são parte da construção do imaginário infantil sobre o que é ser menina (e também sobre o que é ser menino), justifica-se supor que expressões e conteúdos que desfaçam o arquétipo da princesa contribuam para a dissolução dos efeitos retrogressivos de uma normatividade baseada na divisão estritamente binária da sexualidade.

Em 1977, o primeiro seriado de animação da TV brasileira tem por título o nome de uma personagem feminina fora do estereótipo da bela, recatada e indefesa: Mônica é dentuça, gordinha, não leva desaforo para casa ou deixa que façam pouco caso dela. Portanto, aqui, as animações já surgem rompendo padrões de feminilidade submissa, e, mesmo que não seja tendência geral, várias outras animações têm seguido esta mesma direção: Kika, Lili, Luna, Nara e Anabel mostram a seu público-alvo - crianças e adolescentes - que a verdadeira aceitação deve ser pessoal, sem inquestionadamente seguir o que a sociedade diz ou espera como o correto. As protagonistas, ao afirmarem sua singularidade, se mostram aptas à resolução de problemas e situações sem contar com algum príncipe salvador. Isso não significa que as personagens femininas tenham que ser sempre fortes e com total controle sobre si mesmas (Castro, 2016), pois situaria em posição descabida tanto 
personagens ficcionais quanto mulheres reais.

A chegada de Mônica à TV trouxe uma representação feminina afirmativa, certamente resultante do contexto histórico, político e social do Brasil e do mundo, em meados das décadas de 1960 e 1970 (a chamada "segunda onda feminista"). O público não estava tão receptivo a uma personagem (nacional) feminina submissa, já buscava atitudes midiáticas explícitas de não aceitação das imposições de caráter ditatorial em vigor. E como os acontecimentos não têm a clareza que podemos supor ao considerar em retrospectiva, fica para outro momento pensar sobre alguns comportamentos de Mônica. Por exemplo, o uso da violência como resposta ao bullying que sofria.

\section{Referências}

ATHAYDE, Marco A. S. de. Cinema de animação no Brasil: história e indústria moderna. 2013. 73 f. Monografia (Curso de Comunicação Social-Audiovisual) - Faculdade de Comunicação Social, Universidade de Brasília, Brasília - DF, 2013.

BERNARDET, Jean-Claude. Cinema brasileiro: propostas para uma história. São Paulo: Companhia das Letras, 2009.

CAMARGO, Gilson. $\mathbf{O}$ século da animação brasileira. 2017. Disponível em: <http://www.extraclasse.org. br/edicoes/2017/03/o-seculo-da-animacao-brasileira>. Acesso em: 02 abr. 2017.

CASTRO, Lidiane N. de. Feminismo e conto de fadas: uma análise do filme Frozen. Revista Philologus, Rio de Janeiro, Ano 22, n.64 Supl.: Anais do VIII SINEFIL. CiFEFiL, jan./abr.2016.
COSTA, Ana Alice Alcantara. O movimento feminista no Brasil: dinâmicas de uma intervenção política. Revista Gênero, v. 5, n. 2, 2005. Disponível em: <http://www. revistagenero.uff.br/index.php/revistagenero/article/ view/380/285>. Acesso em: 06 mai. 2017.

FERNANDES, Luiza H. P. Princesas em evolução: a construção da identidade feminina nos contos de fadas do cinema de animação contemporâneo. 2015. 149 f. Dissertação (Mestrado em Letras) - Faculdade de Letras e Artes, Universidade do Estado do Rio Grande do Norte, Pau dos Ferros - RN, 2015.

FRÍVOLO. In: Dicionário Aurélio. Disponível em: <https:// dicionariodoaurelio.com/frivolo>. Acesso em: 22 mai. 2018.

GOMES, Andréia P. História da animação brasileira. Universidade do Estado do Rio de Janeiro: Rio de Janeiro, 2008. Disponível em: <http://doczz.com.br/doc/170601/ hist\%C3\%B3ria-da-anima\%C3\%A7\%C3\%A3o-brasileira -andr\%C3\%A9ia-prieto>. Acesso em: 24 ago. 2018.

LIPOVETSKY, Gilles. A terceira mulher. Permanência e revolução do feminino. São Paulo: Companhia das Letras, 2000.

LOPES, Karina E. L. dos S. Análise da evolução do estereótipo das princesas da Disney. 2015. $52 \mathrm{f}$. Monografia (Curso de Comunicação Social - Publicidade e Propaganda) - Faculdade de Tecnologia e Ciências Sociais Aplicadas, Centro Universitário de Brasília, Brasília - DF, 2015.

MAURÍCIO de Sousa Produções. O projeto \#Donasda-
Rua. 2016. Disponível em: <http://turmadamonica.uol. com.br/donasdarua/projeto.php $>$. Acesso em: 15 abr. 2017.

MORENO, Antônio. A experiência brasileira no cinema de animação. Rio de Janeiro: Artenova, 1978.

PATEMAN, Carole. Críticas feministas a la dicotomia publico/privado. In: CASTELLES, Carme (Org.). Perspectivas feministas en teoria política. Barcelona: Paidós, 1996.

SARTI, Sintia. 0 início do feminismo sob a ditadura no Brasil: o que ficou escondido. In: CONGRESSO INTERNACIONAL DA LASA, 21., 1998, Chicago. Anais... Chicago: Illinois, set. 1998.

SILVA, Rosemeire F. da. De um pioneiro a outro, um salto da tecnologia no cinema de animação brasileiro. São Paulo, 1999. Dissertação (mestrado em Ciência da Comunicação) - Escola de Comunicações e Artes, Universidade de São Paulo.

SOLOMON, Charles (org.). The art of the animated image: an anthology. Los Angeles: The American Film Institute, 1987.

SOUSA, Maurício. A Turma da Mônica não tinha MuIheres. 1996. Disponível em: <http://turmadamonica. uol.com.br/cronicas/a-turma-da-monica-nao-tinhamulheres/>. Acesso em: 10 jul. 2017.

\section{Referências Audiovisuais}

ABREU, Alê. CARVALHO, Fernanda. TESSLER, Tita. $\mathbf{0}$ menino e o mundo. [Vídeo]. Produção de Alê Abreu, 
Fernanda Carvalho e Tita Tessler. Direção de Alê Abreu. Brasil, Filme de Papel, 2013, 80 min. Cor. Son.

BOLOGNESI, Luiz. DE MOURA, Jean Cullen. DE MOURA, Marcelo Fernandes. BODANZKY, Laís. IVANOV, Débora. LACERDA, Gabriel. Uma história de amor e fúria. [Vídeo]. Produção de Luiz Bolognesi, Laís Bondanzky, Débora Ivanov e Gabriel Lacerda. Direção de Luiz Bolognesi, Jean Cullen de Moura e Marcelo Fernandes de Moura. Brasil, Buriti Filmes, Gullane, Cinemation Studios, 2013, 74 min. Cor. Son.

BUCK, Chris. LEE, Jennifer. DEL VECHO, Peter. Frozen: uma aventura congelante. [Vídeo]. Produção de Peter Del Vecho. Direção de Chris Buck e Jennifer Lee. Estados Unidos, Walt Disney Animation Studios, Walt Disney Pictures, 2013, 102min. Cor. Son.

CATUNDA, Celia. MISTRORIGO, Kiko. De onde vem? [Tv-séries]. Produção de Tv PinGuim. Brasil, 2001, 4 min. Cor. Son.

O Show da Luna! [Tv-séries]. Produção de Tv PinGuim. Brasil, 2014, 12min. Cor. Son.

Peixonauta. [Tv-séries]. Produção de TV PinGuim. Brasil, 2009, 12min. Cor. Son.

CLIPS DA TURMA. Natal da Turma da Mônica - Versão Original. 2009. (5min37seg). Disponível em: <https:// www.youtube.com/watch?v=kcU1p_eqpow $>$. Acesso em: 10 jul. 2017.

$\mathrm{COHL}$, Émile. Fantasmagorie. [Filme]. Produção e Direção de Émile Cohl. França, 1908, 1 min30seg. P\&B. Mudo.
DIADAANIMAÇÃO.Trailer-Frivolitá-Mostra Nacional - DIA 2014. 2014. (41seg). Disponível em: <https:// www.youtube.com/watch?v=mfmBu7tjA3U $>$. Acesso em: 10 jul. 2017

ENRICO, Juliano. O irmão do Jorel.[Tv-séries].Produção de Copa Studio. Brasil, 2014, $11 \mathrm{~min}$. Cor. Son.

GEROMINI, Clyde. JACKSON, Wilfred. LUSKE, Hamilton. KINNEY, Jack. DISNEY, Walt. As aventuras de Peter Pan. [Filme]. Produção de Walt Disney. Direção de Clyde Geromini, Wilfred Jackson, Hamilton Luske e Jack Kinney. Estados Unidos, 1953, 77 min. Cor. Son.

GONÇALVES, Álvaro Henriques. Presente de Natal. [Filme]. Produção e direção de Álvaro Henriques Gonçalves. Brasil, 1970, 75min. Cor. Son.

GUERRA, Otto. MACHADO, Marta. Wood \& Stock: sexo, orégano e rock'n'roll. [Filme-vídeo]. Produção de Otto Guerra e Marta Machado. Direção de Otto Guerra. Brasil, Otto Desenhos Animados, 2006, $81 \mathrm{~min}$. Cor. Son.

HAND, David. COTTRELL, William. JACKSON, Wilfred. MOREY, Larry. PEARCE, Perce. SHARPSTEEN, Ben. DISNEY, Walt. Branca de neve e os sete anões. [Filme]. Produção de Walt Disney. Direção de David Hand, William Cottrell, Wilfred Jackson, Larry Morey e Perce Pearce. Estados Unidos, Walt Disney Productions, 1937, $83 \mathrm{~min}$. Cor. Son

HARRES, Pedro. GUERRA, Otto. MACHADO, Marta. Castillo y el armado. [Vídeo]. Produção de Pedro Harres, Otto Guerra e Marta Machado. Direção de Pedro Harres. Brasil, Otto Desenhos Animados, 2014, $14 \mathrm{~min}$. P\&B. Son.
LASSETER, John. ARNOLD, Bonnie. GUGGENHEIM, Ralph. Toy Story. [Vídeo]. Produção de Bonnie Arnold e Ralph Guggenheim. Direção de John Lasseter. Estados Unidos, Pixar Animation Studios, Walt Disney Pictures, 1995, $81 \mathrm{~min}$. Cor. Son.

LATINI, Anélio. Sinfonia Amazônica. [Filme]. Produção e direção de Anélio Latini. Brasil, 1953, 61 min. P\&B. Son.

LIEBAN, Andrés. Meu AmigãoZão. [Tv-séries]. Produção de 2D Lab e Breakthrough Animation. Estados Unidos, Canadá, Brasil, 2010, $11 \mathrm{~min}$. Cor. Son.

LUMIÈRE, August. LUMIÈRE, Louis. Chegada do trem à estação. [Filme]. Produção e Direção de Auguste e Louis Lumière. França, 1895, 49seg. P\&B. Mudo.

MAURO, Humberto. INCE. O dragãozinho manso. [Filme]. Produção de Instituto Nacional de Cinema Educativo (INCE). Direção de Humberto Mauro. Brasil, 1942, 25min37seg. P\&B. Son.

MATSUDA, Leo. DISNEY STUDIOS. Cabeça ou Coração. [Vídeo]. Produção de Disney Studios. Direção de Leo Matsuda. Estados Unidos, Pixar Animation Studios, Walt Disney Pictures, 2016, 7min. Cor. Son.

MENDES, André Costa. Desenhando o Brasil: Uma história Animada. Direção: André Costa Mendes. São Paulo, SP: Trabalho de conclusão de curso da Universidade Metodista de São Paulo, 2013. (27 min), son., color, e p\&b, som original. Disponível em: $<$ https:// www.youtube.com/watch?v=q1W7IZ6ACoA $>$. Acesso em: 01 abr. 2017.

MENDES, Elizabeth. $\mathbf{O}$ diário de Mika. [Tv-séries]. Produção de SuperToons. Brasil, 2015, 7min. Cor. Son. 
MUNHOZ, Paulo. Brichos. [Filme-vídeo]. Produção e direção de Paulo Munhoz. Brasil, Tecnokena, 2007, $77 \mathrm{~min}$. Cor. Son.

NAKASHIMA, Yppe. RENOLDI, Silvio. ARAUJO, Mário. ARAUJO, João Luiz. WATANABE, T. Piconzé. [Filme]. Produção de Yppe Nakashima, Silvio Renoldi, Mário Araujo, João Luiz Araujo e T. Watanabe. Direção de Yppe Nakashima. Brasil, 1972, 75min. Cor. Son.

NICOLOSI, Ari. Zica e os Camaleões. [Tv-séries]. Produção de Cinema Animadores. Brasil, 2010, 11 min. Cor. Son.

SÁ, Luiz. Virgulino apanha. [Filme]. Produção e direção de Luiz Sá. Brasil, 1938, 58seg. P\&B. Mudo.

SALDANHA, Carlos. ANDERSON, Bruce. DAVIS, John. FORTE, Lori. STETLER, Lisa Marie. O Touro Ferdinando. [Vídeo]. Produção de Bruce Anderson, John Davis, Lori Forte e Lisa Marie Stetler. Dieção de Carlos Saldanha. Estados Unidos, Blue Sky Studios, Davis Entertainment, Twentieth Century Fox, 2017, 108min. Cor. Son.

SAREMBA, Clewerson. GÓES, Moacyr. BORGES, Wilson. TRINDADE, Diler. Xuxinha e Guto contra os monstros do espaço. [Filme-vídeo]. Produção de Wilson Borges e Diler Trindade. Direção de Clewerson Saremba e Moacyr Góes. Brasil, Diler \& Associados, Globo Filmes, Twister Studios, 2005, 85min. Cor. Son.

SOUZA, Maurício de. KHOURI, Walter Hugo. BARRELA, Eduardo. JANEQUINE, Agostino. Mônica e a sereia do rio. [Filme].Produção de Eduardo Barrela e Agostino Janequine. Direção de Maurício de Souza e Walter Hugo Khouri. Brasil, Maurício de Souza Produções Cinematográficas, Black \& White \& Color, 1987, 60min. Cor. Son.
STAMATO, João. SEEL, Luiz. Macaco feio, macaco bonito. [Filme]. Produção e direção de João Stamato e Luiz Seel. Brasil, 1929, 4min4seg. P\&B. Mudo.

UM FILMES. O CINEMA ANIMADO- “O Kaiser" de Seth / 1917. 2015 (24s). Disponível em: <https://www.youtube. com/watch?v=7NN6TPtL9Zw>. Acesso em: 10 jul. 2017.

URBES, Rosana. PROENÇA, Belisa. Guida. [Vídeo]. Produção de Belisa Proença. Direção de Rosana Urbes. Brasil, 2014, 12min. Cor. Son.

VIDEO BRINQUEDO. Escola de Princesinhas. [TV-séries]. Produção de Video Brinquedo. Brasil, 2007, 15min. Cor. Son.

VIEIRA, Clóvis. DEROSSI, Ereclina. DE ROSSI, Nello. MÜLLER, Tânia. UNGAR, Ester. Cassiopeia. [Vídeo]. Produção de Ereclina de Rossi, Nello de Rossi, Tânia Müller eEster Ungar. Direção de Clóvis Vieira. Brasil, NDR Filmes e Produções, 1996, 80 min. Cor. Son.

YABU, Fábio. Princesas do mar. [Tv-séries]. Produção de Flamma Films, Neptuno Films, Southern Star Entertainment. Brasil, Austrália, Espanha, 12min. Cor. Son.

Notas

1 Doutor em Comunicação pela Universidade Federal do Rio de Janeiro (1992). Mestre em Comunicação pela Universidade Federal do Rio de Janeiro (1983). Pós-doutor pela Universidade Nova de Lisboa (2006). Professor titular da Faculdade de Comunicação e do Programa de Pós-graduação em Comunicação da Universidade Federal de Juiz de Fora (Universidade Federal de Juiz de Fora, Faculdade de Comunicação, Comunicação e Artes Cea. Campus Universitário - Ci- dade Universitária. Martelos. Cep: 36036-330 - Juiz de Fora, MG - Brasil). E-mail: potiguaramsj@@uol.com.br.

2 Mestranda em Comunicação pela Universidade Federal de Juiz de Fora (2017). Graduada em Jornalismo pela Universidade Federal de Juiz de Fora (2016). (Universidade Federal de Juiz de Fora, Faculdade de Comunicação, Comunicação e Artes Cea. Campus Universitário Cidade Universitária. Martelos. Cep: 36036-330 - Juiz de Fora, MG - Brasil). E-mail: laryssaprado@live.com.

3 Jornal cinematográfico mudo realizado pela companhia Marc Ferrez \& Filhos, e exibido no Cine Pathé, no Rio de Janeiro.

4 Fundadores dos Fleischer Studios, em 1921, reconhecidos pela criação de Betty Boop e Popeye.

5 Técnica que utiliza a disposição sequencial de fotografias diferentes de um mesmo objeto inanimado para simular o seu movimento.

6 “(...) [lei de incentivo] 1932 de Getúlio Vargas na qual filmes nacionais seriam obrigatoriamente inclúídos na programação cada mês, ou em 1939 onde 'Os cinemas são obrigados a exibir anualmente, no mínimo, um filme nacional de entrecho e de longa metragem'. Ou a de 1946 na qual 'Os cinemas são obrigados a exibir anualmente, no mínimo três filmes nacionais de entrecho e de longa metragem, declarados de boa qualidade pelo SCDP, do Departamento Federal de Segurança Pública', citando apenas algumas" (Gomes, 2008, p. 21-22).

7 Criações de Ernesto Stilpen, Antônio Moreno, José Rubens Siqueira, Helvécio Ratton, Fausto Hugo Prats, 
Luiz Bandeira de Melo, Marcos Magalhães, entre outros.

8 Ainda existem divergências quanto a esses dados. A Disney afirma que Toy Story é que detêm o título de precursor no gênero longa em animação totalmente computadorizado.

9 O grande salto se deve ao fato de que os maiores investimentos em animação estavam no setor publicitário, não no televisivo, visto que as emissoras compravam programas estrangeiros por valor menor do que custaria a encomenda de um produto nacional. 